\title{
MANAGING CENTRIFUGAL PUMP RELIABILITY IN THE CONTEXT OF TOTAL COST OF OWNERSHIP
}

\author{
J. van der Poel ${ }^{1}$ and C.C. van Waveren ${ }^{2}$ \\ ${ }^{1}$ Department of Engineering and Technology Management \\ University of Pretoria, South Africa \\ johan.vanderpoel@sasol.com \\ ${ }^{2}$ Department of Engineering and Technology Management \\ University of Pretoria, South Africa \\ corro@up.ac.za
}

\begin{abstract}
The management of a population of centrifugal pumps in the petrochemical industry can be daunting. A popular method for strategically optimizing the maintenance and operation of these centrifugal pumps is to measure the reliability of the whole pump population in terms of Mean-Time-Between-Failures (MTBF). Too often MTBF improvement becomes the focus rather than a means of supporting the actual goal, namely Total Cost of Ownership (TCO) reduction. An increase in MTBF is intuitively associated with a reduction of TCO, but this is not necessarily true. This study proposes that the 'MTBF vs time' and 'TCO vs MTBF' curves are characteristics of a specific industrial plant. A tool for approximating the optimum TCO vs MTBF for a plant is introduced, and a qualitative framework for managing pump reliability in the TCO context is proposed.
\end{abstract}

\section{OPSOMMING}

Die bestuur van 'n sentrifugale pomppopulasie in die petrochemiese bedryf kan oorweldigend wees. 'n Populêre metode om die instandhouding en bedryf van hierdie sentrifugale pompe op 'n strategiese vlak te optimiseer, is om die betroubaarheid van die pomppopulasie in geheel, in terme van Gemiddelde-TydTussen-Falings (GTTF), te meet. Die fokus word te veel op die verbetering van die GTTF geplaas en nie op die eintlike doel, naamlik die vermindering van Totale Koste van Eienaarskap (TKE) nie. ' $n$ Verbetering in die GTTF word intuïtief geassosieer met 'n vermindering van TKE, maar dit is nie noodwendig waar nie. Hierdie studie stel voor dat die 'GTTF vs Tyd'-kurwe en 'TKE vs GTTF'-kurwe kenmerkend is van 'n spesifieke industriële aanleg. 'n Instrument om die benaderde optimum TKE vs GTTF vir 'n aanleg te bepaal, asook 'n kwalitatiewe raamwerk om pomp betroubaarheid in die TKE konteks te bestuur, word voorgestel.

\footnotetext{
${ }^{1}$ The author was enrolled for the M Eng (Engineering Management) at the Department of Engineering and Technology Management, University of Pretoria
} 


\section{INTRODUCTION}

Second to the electrical motor, the centrifugal pump is the most common piece of equipment in the petrochemical industry [1], and the centrifugal pump population for a typical petrochemical plant could easily amount to thousands [2]. Because of its relatively simple operation, the centrifugal pump is unlikely to be easily replaced in the near future. Therefore the reliability of these pumps is essential for the stable operation of all petrochemical plants.

In general, to increase reliability centrifugal pumps are duplicated by means of a standby pump, and in some critical applications a complete spare centrifugal pump can also be kept in storage. For this reason pump failures usually do not cause large production losses. The consequence of the extent of redundancy is that the reliability of pumps is often taken for granted - to the point where, in extreme cases, the pumps are sacrificed to other process equipment or the process itself. The danger of this way of thinking about pump maintenance and its operation is that the expenditure on centrifugal pumps may be either too much or too little. Instead of sacrificing or improving pump reliability indefinitely, the reliability of a population of pumps should rather be managed by investigating its reliability, and the impact on the bottom line within the context of Total Cost of Ownership (TCO). In addition, the pump population needs to be managed on a systems level, since pump maintenance managers usually do not have the capacity to do a detailed analysis of each individual pump.

The objectives of this study was therefore to find a method or framework to manage the reliability of a population of centrifugal pumps in the Total Cost of Ownership context, and to supplement this framework with a management tool that could assist the centrifugal pump maintenance manager in his day-to-day management activities.

\section{RELIABILITY AND TOTAL COST OF OWNERSHIP}

\subsection{Total Cost of Ownership}

The Total Cost of Ownership (TCO) is a concept by which all costs associated with a capital purchase over a given time period are accounted for in the value assessment of the asset. It is often regarded as the cost of owning and operating an existing asset at a given point in time, and therefore consists of all the direct and indirect costs incurred throughout the life cycle of an asset, including acquisition, deployment, operation, support, and retirement [3].

The TCO of a commodity is defined as all costs associated with the commodity over its life time, but calculated only for a predefined time period, i.e. per year, and not for the entire life of the commodity. The TCO of any commodity is thereby divided into four categories:

- Direct expenditure on the commodity, e.g. acquisition cost as well as pump spares;

- Expenditures on other related commodities, e.g.. pump electricity usage; 
- Internal costs, e.g. internal labour on pump overhauls; and

- Opportunity costs, e.g. production losses due to pump failures.

These four categories make up the TCO of the commodity, as depicted in

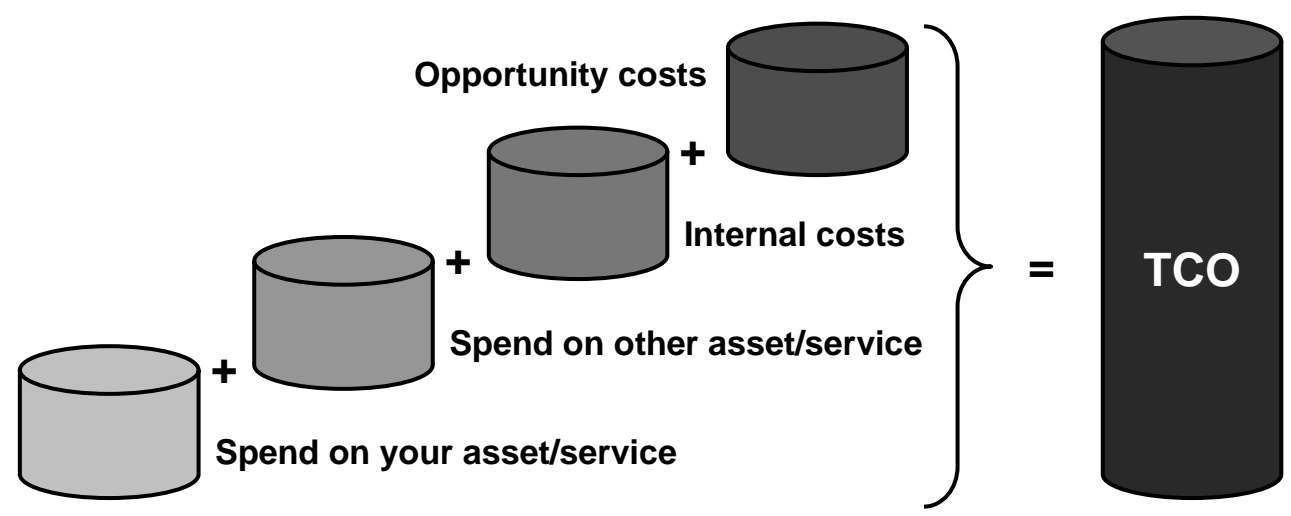

Figure 1: TCO categories

\subsection{Mean-Time-Between-Failure (MTBF)}

The measurement of Mean-Time-Between-Failure (MTBF) as a means to trend the reliability fluctuation of an item is commonly used in industry. The MTBF is based on the number of failures per unit time; and for a population of similar items (e.g. centrifugal pumps) it is defined as the total number of pumps in a population divided by the number of failures during the measurement interval. For centrifugal pumps the measurement interval is typically given in months. The MTBF for a population of centrifugal pumps is calculated using Equation 1.

$$
M T B F=\frac{\text { Number of Pumps }}{\text { Number of Failures per Month }}
$$

Centrifugal pumps can typically have MTBFs of 72 pump months per failure. In engineering language, the units of 'pump months' and 'per failure' are usually omitted: only the number of months is stated - e.g. '72 months'. It is important to note that a 'pump month' is not the same as a calendar month. So Equation 1 is usually restructured as indicated in Equation 2.

$$
\text { MTBF }=\frac{\text { Number of Pumps } \times \text { Months }}{\text { Number of Failures }}
$$

In theory, the MTBF should only be applied to random failures that occur at a constant failure rate, as indicated in Figure 2 [4]. In practice this is virtually impossible, for two reasons: 
- It is impossible to distinguish between infant failures, random failures, and wearout failures across the board, and

- It is very difficult to collect any data on infant failures, random failures, and wearout failures.

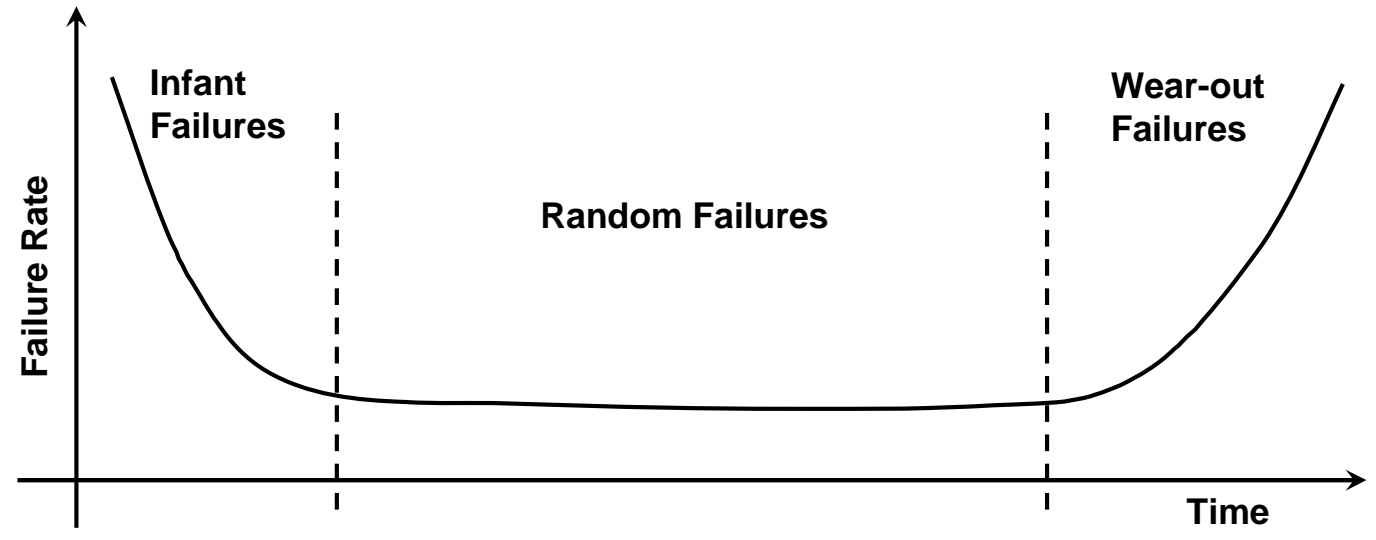

Figure 2: A typical bathtub failure rate curve

The MTBF values produced for centrifugal pumps, including seals, bearings, and couplings, are a mixture of all three failure rate phases, but segregating the failures into the three different phases remains important, as such segregation will:

- Greatly aid in the understanding of failures and the consequent improvements in MTBF through corrective actions, and

- Enable the development of the ideal life cycle for the equipment.

The MTBF improvement initiative could therefore be staged according to the three phases of the failure rate curve - first, by eliminating the infant failures ('bad actors'), then by minimizing the random failures, and last, by reaching and extending the wear-out failures. Currently, centrifugal pumps and pump components rarely reach the wear-out phase, which is evident from the fact that many thousands of pumps achieve an MTBF of only 1 year [1]. Centrifugal pumps are designed for a service life of twenty years and at least 3 years of uninterrupted operation [5].

To make Equation 1 more suitable as a management tool with which to trend pump reliability improvement, the calculation must be smoothed over a certain period. The periods most commonly used are either six months or twelve months. This leads to Equation 3 for MTBF.

$$
M T B F=\frac{\text { Number of Pumps (On a } 6 \text { or } 12 \text { month moving average) }}{\text { Number of Failures per Month (On a } 6 \text { or } 12 \text { month moving average })}
$$

The decision whether to use six or twelve months makes no difference to benchmarking, since both could be calculated from the same set of input data. However, it has important practical implications for human behaviour, which is driven by performance measurements. Budgets usually run for twelve months, and if 
the MTBF is calculated on a six month moving average, it could be manipulated to coincide with the financial year. This is especially pertinent in situations where MTBF is one of the personal performance measurements of maintenance personnel. For instance, it could happen that if the MTBF is based on a six month moving average, that pump maintainers decide to overhaul as many pumps as possible during the first six months of the financial year, where an overhaul is regarded as a failure, and this results in a major drop in MTBF. During the second six months no overhauls are done, however, and maintainers can 'sit back' and watch the MTBF soar to new heights - just in time for merit appraisals at the end of the financial year. A twelvemonth moving average therefore seems more conducive to reliability improvement, and should preferably be used throughout the petrochemical industry as a way to measure and benchmark the reliability status and improvement of a population of pumps. Effectively Equation 3 trends the number of failures per month, taking into the consideration the size of the population of pumps being measured.

Although Equation 3 is an excellent tool for measuring MTBF trends, it is a poor tool for measuring relative reliability. Different plants have different substances that need to be transported. Depending on the substance, the MTBF could be inherently high for 'easy' substances (e.g. water and solvents) or low for 'difficult' substances (e.g. tar or slurry). A pump with a low MTBF might therefore be acceptable within the larger total plant cost environment or in the TCO context.

\subsection{Pump characteristics}

According to Bloch [6], the reliability of a pump will be at its best when the pump is operated at its Best-Efficiency-Point (BEP). Every pump has only one BEP for a specific system resistance, and this BEP is dependent on the speed and diameter of the impeller. Bloch [6] proposes a reliability model where the reliability curve is superimposed on a pump curve (as depicted in Figure 3) and where the optimum reliability will be attained at the BEP. The model does not necessarily imply that optimum pump reliability is the ultimate goal, but it does propose that in the context of the pump's reliability, operating at the BEP will result in the longest uninterrupted operation of the pump.

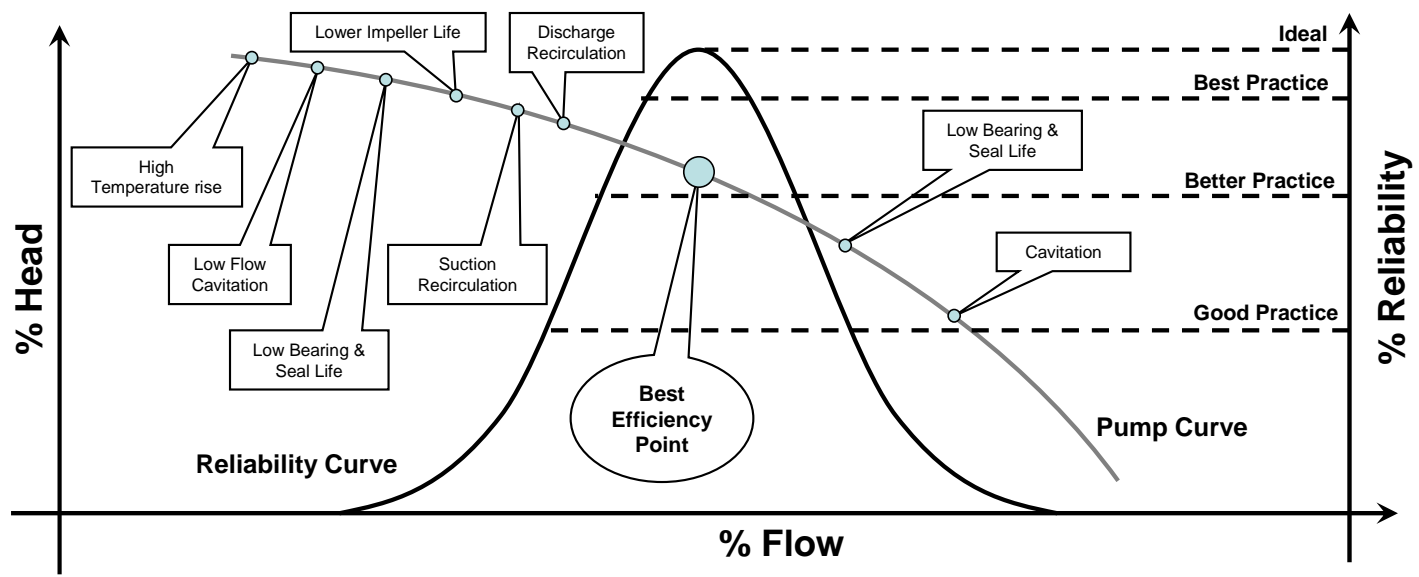

Figure 3: Pump characteristics and reliability 
From both practical and total cost efficiency viewpoints, running a pump at its BEP is not always viable. Therefore, pumps are not always being selected to operate at their BEP, and the throughput of processing plants also does not stay constant. Process de-bottlenecking, organizational culture, and economics could lead to pumps being operated on the right hand side of the pump curve in order to obtain more flow - which is to the detriment of the pump, but benefits production income. In most cases the extra production income gained through higher flow far outweighs the benefits of having a more reliable pump. If production losses are therefore part of TCO, then a higher reliability does not necessarily result in lower TCO, which contradicts O'Connor [4]. Balancing the economic impact of more production with increased maintenance requires a management tool with which to view pump reliability in the TCO context.

\section{AN HOLISTIC MANAGEMENT FRAMEWORK}

From the above, the concept of MTBF and reliability improvement decisions must be viewed in an holistic way. It is possible to keep a systems perspective by evaluating MTBF and making reliability improvement decisions in the TCO context. For this reason, the MTBF and its behavior over time must be investigated, as well as its effect on TCO.

\subsection{MTBF vs time}

If an MTBF improvement initiative is plotted against time, one can intuitively argue that the relationship should take the form of the S-curve or learning curve, as depicted in Figure 4. Initially the improvement is slow, owing to cultural inertia such as training, implementation obstacles, and other organizational issues; but then the rate of improvement increases as personnel become more accustomed to the new methodology. The improvement rate slows down thereafter, and a lot more time and moneys need to be spent in order to obtain further improvements, which can again follow the shape of a new S-curve.

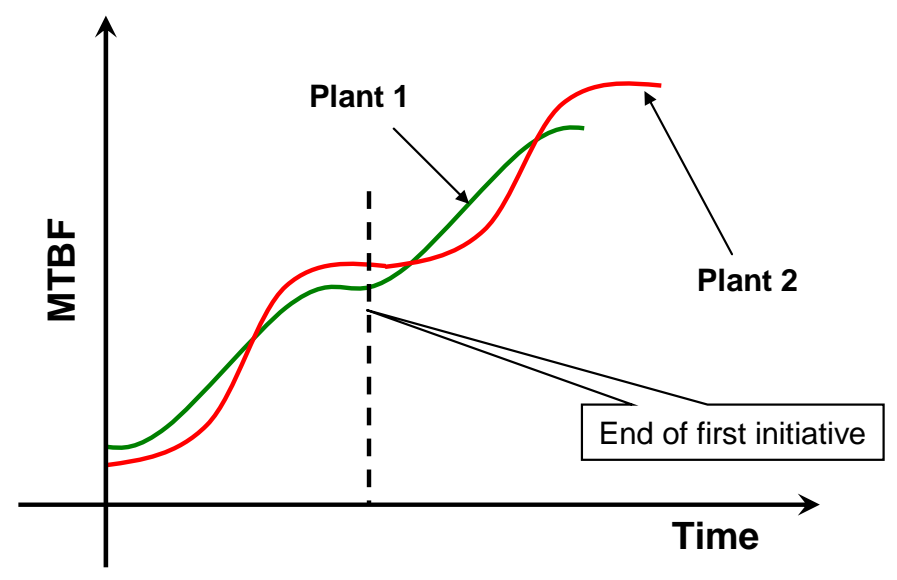

Figure 4: MTBF vs. time 
If the mathematical model of the S-curve for a specific plant is known, one can be more accurate in forecasting possible MTBF improvements, enabling budget owners to do more accurate projections of future cost. This model also proposes that different plants will have different S-curves, as depicted in Figure 4 . This will be because different plants transport different substances, have different maintenance and production cultures, and have different budgets with which to drive MTBF improvement. It is proposed that plant-specific MTBF improvement over time be regarded as a characteristic of that specific plant - that is, Plant 1 has a different MTBF improvement characteristic from Plant 2.

\subsection{MTBF in the TCO context}

A detailed breakdown of the TCO for a population of centrifugal pumps in the petrochemical industry can be compiled, as depicted in Figure 5. The breakdown can be used as a framework for managing the reliability of pumps in the TCO context; and although this framework is more qualitative than quantitative; it can be modified to include more detail by quantifying certain important sub-categories for the purposes of calculating potential TCO benefit. The detailed TCO breakdown will also aid the pump manager in keeping a total systems perspective, especially when making decisions and evaluating the possible consequences for the TCO of pumps.

\begin{tabular}{|c|c|c|c|}
\hline Production losses & \multirow[b]{3}{*}{ Opportunity Costs } & \multirow[b]{2}{*}{ Direct Spend } & \multirow{2}{*}{$\begin{array}{l}\text { Projects }{ }_{\mathbb{1}_{\oplus}} \\
\text { Reconditioning } \\
\text { Replacement }\end{array}$} \\
\hline $\begin{array}{l}\text { Product losses due } \\
\text { to leaks }\end{array}$ & & & \\
\hline $\begin{array}{l}\text { Capital tied down } \\
\text { due to pump } \\
\text { over/under } \\
\text { population }\end{array}$ & & & $\begin{array}{l}\text { Condition } \\
\text { Monitoring } \\
\text { Equipment }\end{array}$ \\
\hline $\begin{array}{l}\text { Lack of Front end } \\
\text { loading }\end{array}$ & \multirow{11}{*}{\begin{tabular}{|l|l} 
ort & \\
ost & Internal Spend \\
ost & \\
$\mathrm{D}$ & \\
air &
\end{tabular}} & & $\frac{\text { Civils }}{\oplus}_{\text {Tools }}$ \\
\hline $\begin{array}{c}\text { Too many } \\
\text { workshops }\end{array}$ & & & $\begin{array}{l}\text { Alignment tools } \\
\text { Tracking }\end{array}$ \\
\hline${ }_{\oplus}$ Incorrect process control & & TCO & Casting Patterns \\
\hline Internal & & \multirow{8}{*}{ Related Costs } & Consultants \\
\hline $\begin{array}{l}\text { Manufacture } \\
\text { (machine shop) }\end{array}$ & & & $\begin{array}{l}\text { Reverse } \\
\text { Engineering }\end{array}$ \\
\hline Reliability Grou] & & & Energy $_{\oplus}$ \\
\hline Technical Suppor & & & System components \\
\hline$\underline{\text { Stock Holding cos }}$ & & & other than pump \\
\hline Transaction cos & & & spare \\
\hline Design R\&I & & & Painting $_{\oplus}$ \\
\hline Internal Repai & & & Purging/cleaning \\
\hline
\end{tabular}

Figure 5: TCO of a centrifugal pump population 
The ideal is to be able to measure true TCO accurately. Unfortunately, most Enterprise Resource Planning (ERP) systems do not lend themselves to the accurate and easy measurement of TCO with the detail required for making informed decisions about MTBF in the TCO context. Because of this difficulty of calculating the true TCO in the operational environment, the calculations in this study were limited to the maintenance activities pertaining to a pump failure, and the corresponding Total Maintenance Cost (TMC) was obtained from the ERP system. The TMC used in this study included artisan labour cost for preventive maintenance, auxiliary repairs and pump overhauls, pump spares, rigging, scaffolding and crane cost, and special services like coating and machining.

It is important to note that, although mechanical seal costs are one of the highest expenditures in pump failures, they were not included in the research, as the petrochemical company under consideration is in alliance with the mechanical seal supplier, which supplies all seals on a fixed fee basis. The mechanical seal cost is therefore not a variable in the data that were extracted from the ERP system.

Consequently this study attempted to demonstrate whether the trends experienced with TMC are a suitable approximation of the trends that could be expected with regard to TCO reduction through managing only TMC.

If TMC is plotted against MTBF, one can intuitively argue that the relationship should take the form of the curve depicted in Figure 6. The curve suggests that the TMC might increase initially to improve MTBF, but eventually the TMC should be reduced as the MTBF of pumps improves. However, the reduction in TMC will not continue indefinitely, since there will be a point where minimal expenditure is necessary in order to sustain the MTBF at this corresponding level. Beyond this point, the TMC will increase again in order to improve the MTBF further. The ideal is to manage the MTBF in the vicinity of the optimum TMC point, as indicated by the control region in Figure 6.

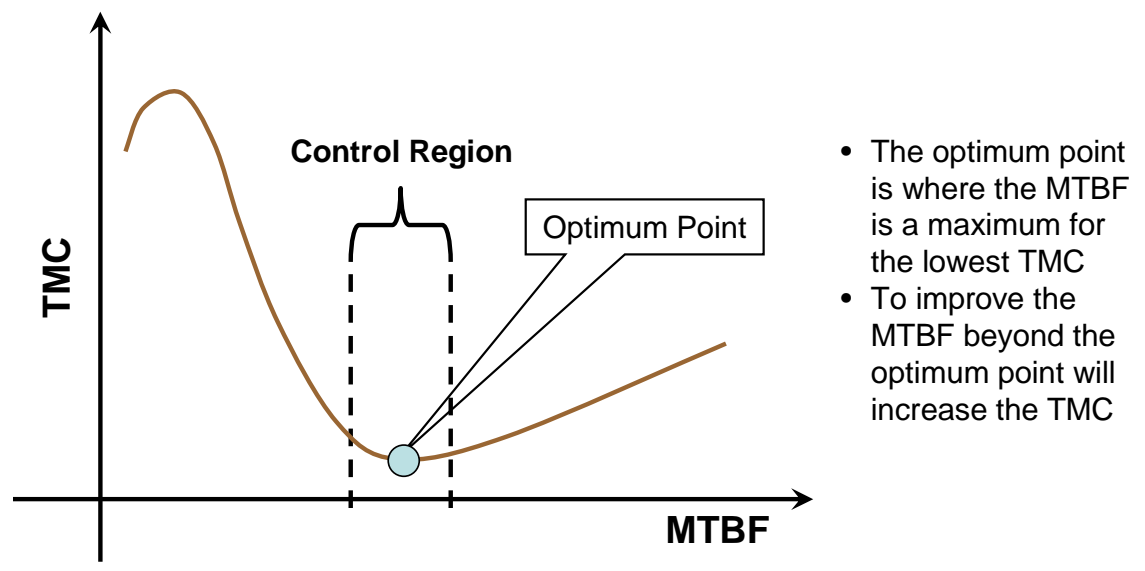

Figure 6: Optimum TMC vs MTBF 
The optimal TMC vs MTBF graph can also be seen as plant-specific, with different plants having different optimal TMC vs MTBF graphs. The conjecture is that the 'Optimum TMC vs MTBF' curve of a specific plant or group of pumps is unique to that plant or group of pumps. The shape and position of the Optimum TMC vs MTBF curve will depend on various factors such as the age of the pumps, substances being pumped, maintenance and production cultures, and the budgets or funds available for MTBF improvement, to name but a few. The implications of this are depicted in Figure 7.

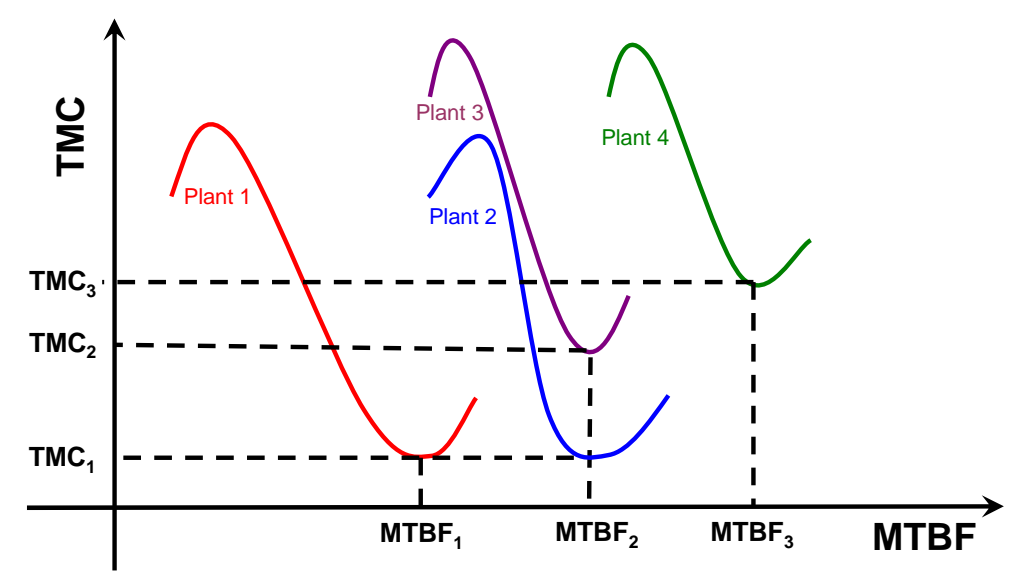

Figure 7: Optimum TMC vs MTBF for different plants

In Figure 7, Plant 1 and Plant 2 have the same optimum TMC, but at different MTBF values. The different (negative) slopes of the two graphs also indicate that the rate of MTBF improvement for Plant 1 is greater than that for Plant 2. Plant 2 and Plant 3 have an optimum point at the same MTBF, but with different optimum TMC values. Plant 4 has the highest MTBF, but also the highest TMC. There can be various other permutations, and from Figure 7 it should be evident that there is no single Optimum TMC vs MTBF curve that can be applied universally. Every plant has its own curve that is characteristic of that specific plant.

Even though Plant 1 and Plant 2 have similar optimum TMC values, this does not mean that the higher MTBF of Plant 2 is not worth striving for. There might be many non-quantifiable benefits of having a higher TMC when striving for a higher MTBF. One of these might be that, although the TMC is higher, the TCO may be lower. Another might be a reduction in the so-called 'nuisance factor' as a result of having to attend to regular (less important) pump failures, and thus losing focus on more critical equipment. Driving higher MTBF values can also increase the overall quality in operation and maintenance through corrective actions and improvement. Striving for a higher MTBF is therefore justifiable, as the ultimate goal is to lower the TCO.

A final remark on the optimal TMC vs MTBF graph is about local optimums. When studying results, the apparent optimum might be a local optimum, and increasing TMC vs MTBF might just be the start of a new cycle of further TMC vs MTBF improvement, as depicted in Figure 8. 


\section{RESULTS}

For the purpose of this study, data from different plants within a petrochemical company were used to evaluate the framework to manage the reliability of a population of centrifugal pumps in the TCO context. The MTBF values were calculated on a twelfth month moving average.

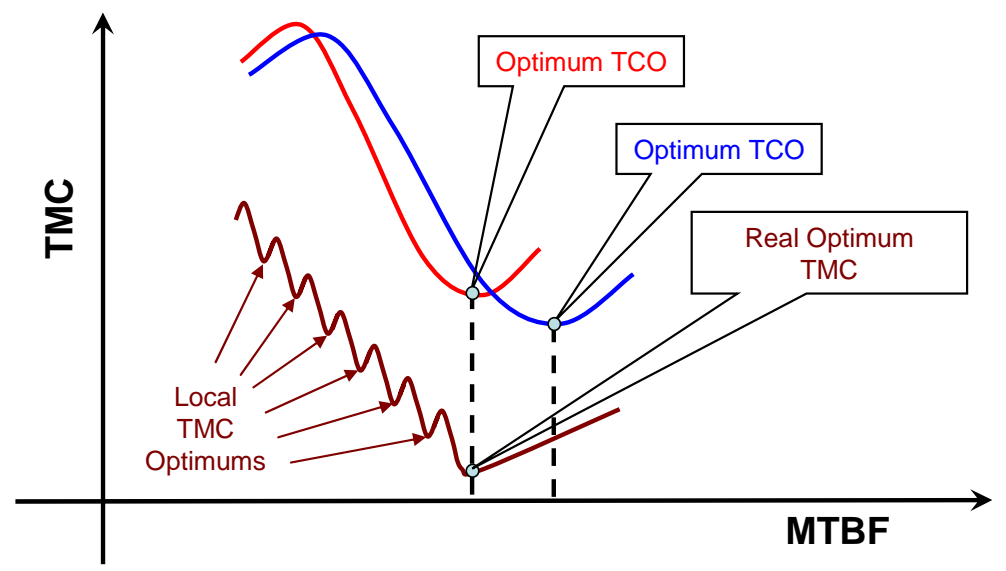

Figure 8: Optimum TMC and TCO vs MTBF

\subsection{MTBF vs Time characteristic}

To evaluate the MTBF vs Time characteristic, two identical plants in terms of pumping application were considered. The first plant had a total of 76 pumps in operation, while the second plant a total of 79 pumps. Any differences between these plants were mainly in terms of operating and maintenance personnel. The MTBF vs Time characteristics for these plants are depicted in Figure 9.

By analyzing data obtained from various other plants, it was concluded that the MTBF improvement over time is a plant-specific characteristic that depends on not only the equipment and the application in which the pumps are used, but also the prevailing attitude and culture of the specific plant personnel towards the management of pumps. At the petrochemical company under consideration, several plants are duplicated. It was found that even though these plants have similar applications, similar pumps, and even similar budgets, the MTBF vs Time and the rate of MTBF improvement differ, as can be seen from the graphs in Figure 9. Often similar plants are benchmarked against each other in terms of MTBF performance, but plant-specific cultural differences must also be taken into consideration. The plants depicted in Figure 9 have an excellent opportunity for best practice sharing, but cultural inertia could prevent these two plants from ever performing at the same level.

Figure 9 highlights that MTBF predictions cannot be done based on historical MTBF vs Time graphs. This was found to be true for all the plants used in this research, 
where none of the plants shows a true S-curve characteristic for MTBF improvement.

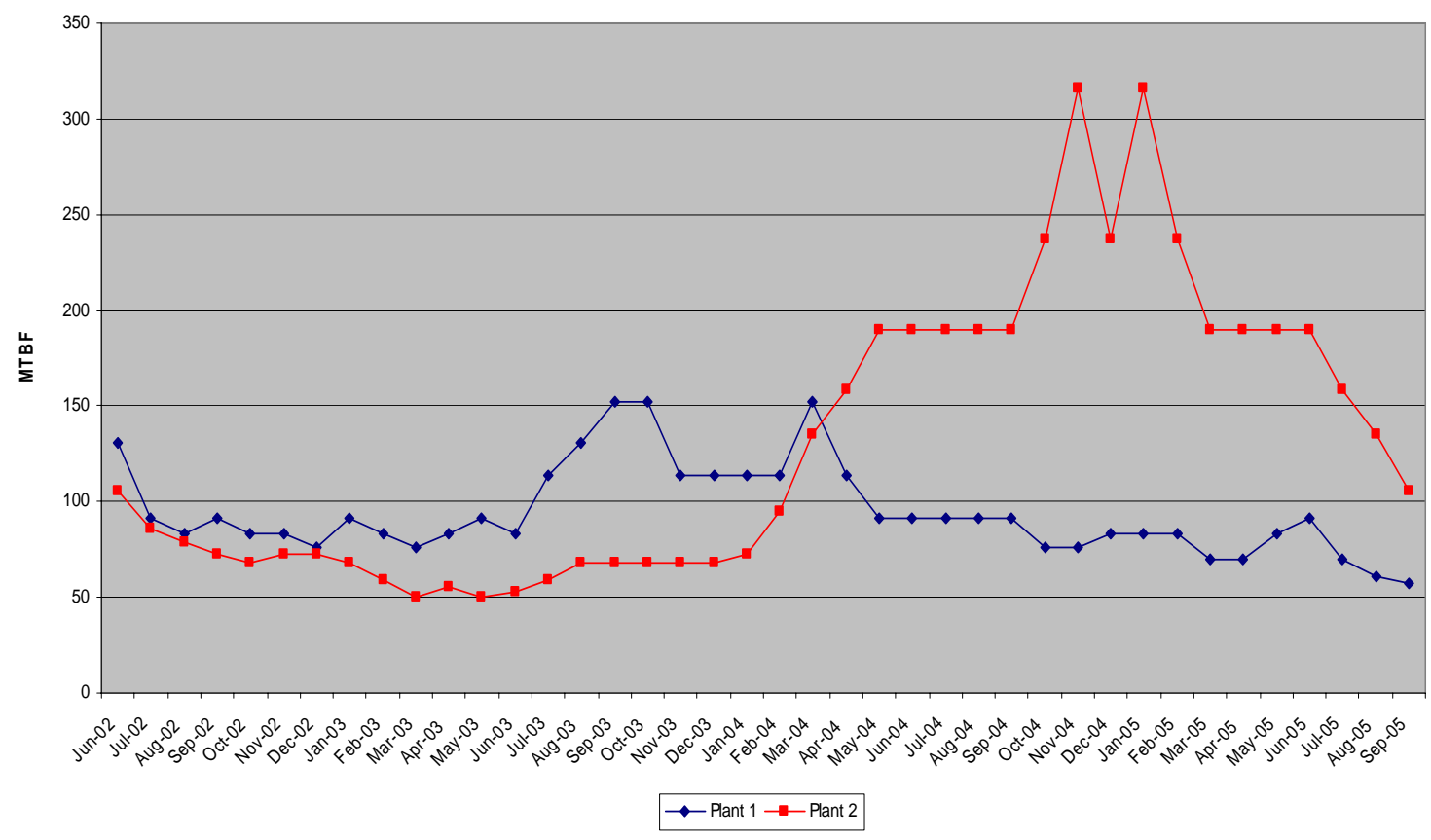

Figure 9: MTBF vs Time characteristic for different plants

\subsection{Total Maintenance Cost vs MTBF characteristic}

To evaluate the TMC vs MTBF characteristic, two identical but different plants were again considered within the same petrochemical company. In this specific case, two tar plants were considered: one is equipped with multi-stage pumps, the other with single-sage pumps. The results for the two plants are shown in Figure 10.

When considering these plants, it is evident (from Figure 10) that, although these plants are identical in the substance being pumped, and both started at the same time with their MTBF improvement initiatives, they have totally different TMC vs MTBF curves. In order to model the behaviour suggested in Figure 6 and 8 , a $6^{\text {th }}$ order polynomial fit was used to trend the data sets. The trend of the multi-stage pumps in Figure 10 indicates that a real optimum MTBF could be expected at about 43 months, preceded by a number of local optimums. One can also envisage that the single-stage pumps could ultimately reach the same optimum MTBF level as the multi-stage pumps. One reason for the difference between the multi-stage and singlestage pumps might lie in the different operating and maintenance cultures. Furthermore, by their nature multi-stage pumps cost more to maintain than singlestage pumps - another possible reason for the steeper negative slope on the multistage pump curve.

Although the TMC vs MTBF characteristics for the different plants differ, it was found that in general the trend is towards lower TMCs for higher MTBFs. Figures 6 and 10 were found to be applicable to all the plants in the study, and so it is concluded that the TMC vs MTBF curve serves as a tool for determining optimum 
TMC vs MTBF.

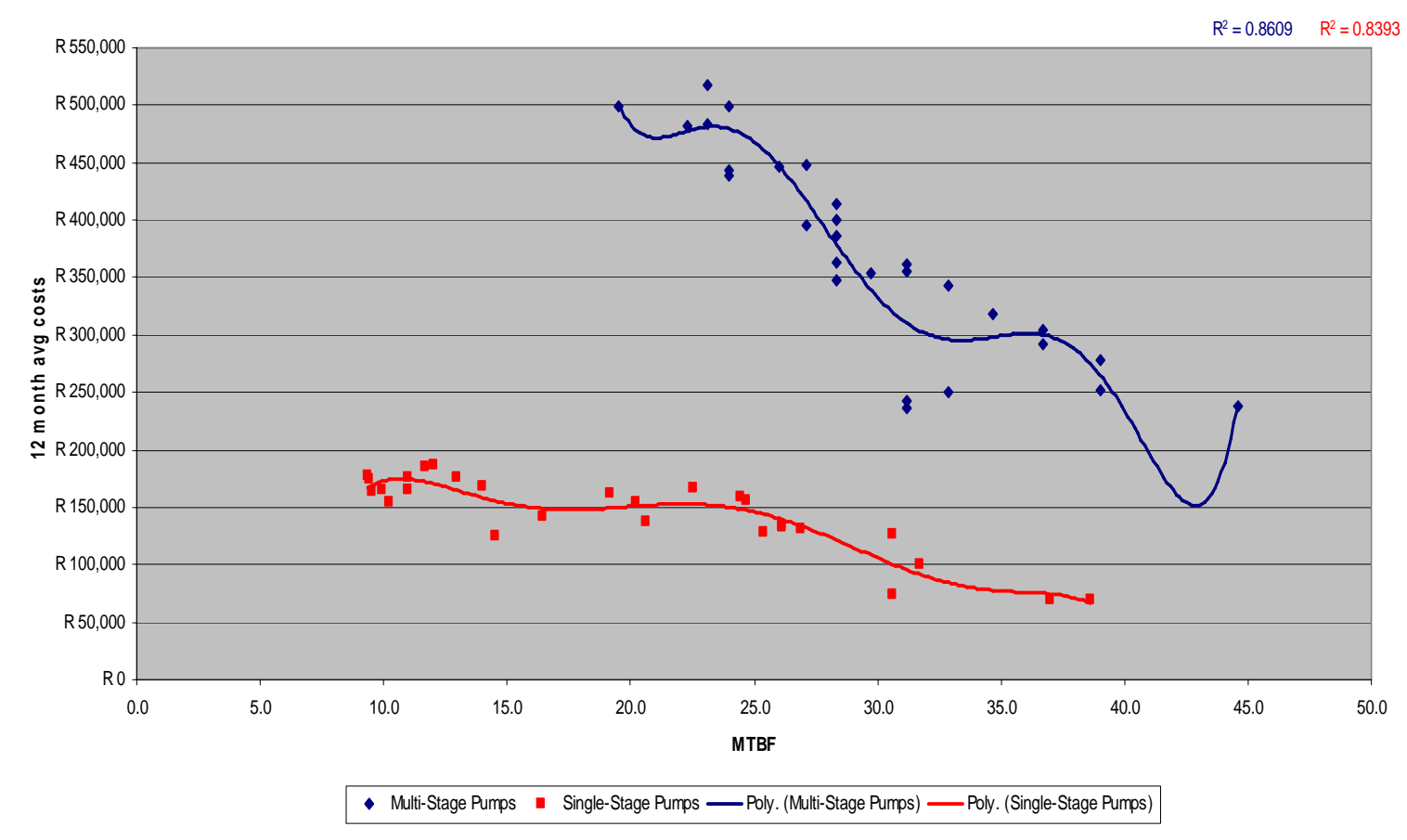

Figure 10: TMC vs MTBF for different tar plants

\section{CONCLUSION}

This paper aimed to define a framework for managing the reliability of a population of centrifugal pumps in the Total Cost of Ownership context, and to supplement this framework with a management tool that could assist the centrifugal pump maintenance manager in his day-to-day management activities.

Figure 10 was found to be a good representation of TMC vs MTBF, but it is limited in terms of managing the reliability of pumps in the TCO context in the sense that TMC is a poor replacement for TCO. If TMC were a good replacement for TCO, then the optimum MTBF with regard to TMC would be the same optimum MTBF with regard to TCO. Using only TMC to determine optimum MTBF leads to the nonutilization of some of the TMC reduction potential. This is because the apparent optimum could be a local optimum, and increasing TMC vs MTBF might just be the start of a new cycle of further TMC vs MTBF improvement. Also, with the concept of lower optimum TCO vs higher MTBF, what could be an optimum TMC is not necessarily an optimum TCO. For instance, a higher MTBF could result in more stable production, resulting in lower TCO. To obtain this higher MTBF it may be necessary to increase TMC. Various other permutations are possible, and thus it is evident that the validity of optimum TMC vs MTBF as a management tool must be carefully considered.

To minimize potential mismatches between TMC and TCO optimums, it is proposed that all MTBF improvement decisions be evaluated using a qualitative framework 
based on the TCO structure. As an example, Figure 11 depicts the TCO structure for a generic plant-wide decision about whether to reduce clearances and tolerances during pump overhauls. The applicable cost elements are marked in red if costs are expected to increase, and in green if they are expected to decrease. Branches marked in black are unlikely to be affected by the decision under consideration (or the effect might be negligible).



Figure 11: TCO structure for reduced clearances and tolerances

Starting with the direct spending branch, the lowest levels on both the internal and external reconditioning costs indicate that the average spares cost might increase, but the number of failures might be reduced. If the effect of reduced failures is prevalent, then the net result will be a TCO reduction on the total spares cost. Closer tolerances and clearances will probably require more quality control, and applying coatings on rotating interfaces will reduce the risk of seizure. The last two actions will result in a localized increase in TCO with regard to services. If successful, this decision will result in higher MTBFs and consequently fewer replacements, resulting in a localized drop in total replacement cost. The combination of all the localized TCO reductions will result in a net reduction in TCO in the direct spending branch.

Following the same rationale with the other branches, all the main branches would equate to a net TCO reduction, thus indicating that on a qualitative level the reduction of tolerances and clearances could be worthwhile. A specific decision, such as one on reducing tolerances and clearances, is highly dependent on the average spares price vs failure reduction. This is one area where more detailed quantification may be necessary, and could be regarded as a Key Performance Indicator. Having tighter tolerances and clearances in rotating equipment will inevitably result in more expensive spare parts. This increase in spares price will have to be measured and compared with the benefit of reduced failures. 


\section{REFERENCES}

[1] Bloch, H.P. (2004). Pump user's handbook life extension, Fairmont Press, Lilburn, GA 30047.

[2] Sasol Review, May 2004, Performance Plus Statistics, Sasol Ltd, South Africa

[3] Bailey, J.T., Heidt S.R. (2003). Business driven information technology: Answers to 100 critical questions for every manager, eds Laube D.R. and Zammuto R.F., Question \#74, Stanford University Press.

[4] O'Connor. P.D.T. (2002). Practical reliability engineering, $4^{\text {th }}$ edition, John Wiley \& Sons Ltd, West Sussex, England.

[5] API Standard 610, (2003), Centrifugal Pumps for Petroleum, Petrochemical and Natural Gas Industries, $9^{\text {th }}$ edition, American Petroleum Institute.

[6] Bloch, H.P. (1998). Improving machinery reliability, $3^{\text {rd }}$ edition, Gulf Publishing Company, Houston, Texas. 